Acta Manilana 64 (2016), pp. 41-50

Printed in the Philippines

ISSN: 0065-1370

\title{
Pulse electrodeposited tin/palladium/exfoliated graphene oxide (Sn/Pd/EGO) catalyst for direct ethanol fuel cell applications
}

\author{
Paulo Irvin A. Chang1, Joshua L. Tan', E Bernard John V. Tongol ${ }^{* 2-4}$
}

${ }^{1}$ Department of Mathematics and Physics, College of Science; ${ }^{2}$ Graduate School; ${ }^{3}$ Department of Chemistry, College of Science; ${ }^{4}$ Research Center for the Natural and Applied Sciences University of Santo Tomas, 1015 Manila, Philippines

\begin{abstract}
This study aims to utilize pulse electrodeposition to synthesize tin/palladium/exfoliated graphene oxide ( $\mathrm{Sn} / \mathrm{Pd} / \mathrm{EGO}$ ) catalyst composite as anode material for ethanol oxidation reaction (EOR) which finds significant application in Direct Ethanol Fuel Cell (DEFC) application. The electrocatalytic activity of the prepared catalysts towards ethanol oxidation was evaluated using cyclic voltammetry in $1 \mathrm{M}$ ethanol in $0.1 \mathrm{M} \mathrm{NaOH}$. Cyclic voltammetry showed that the addition of Sn to Pd improved the catalytic activity of Pd towards EOR in alkaline solution. The bimetallic Sn/Pd catalyst on glassy carbon electrode (Sn/Pd/GCE) showed a higher catalytic activity with a peak current density of $28.1 \mathrm{~mA} \mathrm{cm--2}$, compared to Pd/GCE (23.39 $\mathrm{mA} \mathrm{cm}^{-2}$ ). The electrocatalytic activity of bimetallic Sn/Pd catalyst further improved when EGO was used as a support (Sn/Pd/EGO) with a peak current density of $36.7 \mathrm{~mA} \mathrm{~cm}{ }^{-2}$. Atomic force microscopy revealed that the catalysts were deposited on the edges of the graphene sheets forming bright clusters with dark fringes on the middle of the structure. X-ray photoelectron spectroscopy confirmed the presence of Pd and Sn metals and their oxides. This study demonstrates that pulse electrodeposition could offer a much simpler and faster approach in the development of high performance catalysts for EOR.
\end{abstract}

Keywords: direct ethanol fuel cells, graphene, Sn/Pd, AFM, XPS, pulse electrodeposition

\section{INTRODUCTION}

Research on alternative energy source includes the development of fuel cells. Fuel cells are attractive due to their minimal carbon emission foot print, high theoretical thermodynamic efficiency (not restricted by Carnot limit), and zero use of fossil fuels [1]. With these

*To whom correspondence should be addressed bernard.john.tongol@ust.edu.ph /

bjvtongol@yahoo.com characteristics, fuel cells have high potentials to be used as a primary energy source.

Fuel cells generate electric current through electrochemical reactions with the help of metal based catalysts. Platinum has been reported to have a high catalytic activity compared to other metals and it is often the anode catalyst of choice [2]. However, palladium (Pd) is more preferred because it is cheaper and more abundant than Pt. In addition, Pd has been reported to have a higher catalytic activity towards ethanol 
oxidation reaction than platinum in alkaline media [3, 4]. Moreover, this condition gives a broader option in combining other metal catalyst with palladium [5]. Thus, Pd is more practical in terms of synthesizing catalysts for commercial use.

Palladium as catalyst alone is susceptible to poisoning by carbonaceous species in alkaline medium. To prevent poisoning intermediates to form on the surface of Pd catalyst, it is usually combined with promoter metals [6] by providing necessary intermediates for the reaction due to the bi-functional mechanism [7]. Pd separates ethanol by chemisorption, resulting to an adsorbed carbonaceous species (CO). The promoter reacts with water which leads to the formation of $-\mathrm{OH}_{\text {ads }}$ species that is needed to oxidize $\mathrm{CO}$ at a lower potential which results to its desorption. This frees up more active sites of Pd for the EOR to occur, thus giving higher catalytic activity.

Aside from adding promoters to improve catalytic activity, the catalyst can be deposited on a support material with large surface area such as carbon-based materials [8, 9]. Studies have shown that Pd catalyst supported by graphene gave enhanced catalytic activity [10, 11]. Graphene can improve the performance of the catalyst by providing deposition sites for the (electro)chemical reduction of the catalyst. This results to an effective dispersion of the catalyst particles, leading to a higher effective surface area. A higher effective surface area would provide the catalyst more active sites for the oxidation of the fuel to occur, resulting in a higher catalytic activity [12].

Investigations have suggested that bimetallic catalysts of Pd alloyed with other metals can effectively enhance the electrocatalytic activity towards EOR in alkaline media. Majority of the past research on Pd based catalysts are alloyed with Ni [10, 11, 13], Co [14], Ru [5], Sn [15-17], among others. These studies use chemical methods in the preparation and deposition of the catalysts. There are few reports $[18,19]$ on the use of electrochemical techniques for the deposition of Pd-based catalysts on graphene support. Nagaraju and Suresh [18] electrochemically synthesized Pd nanoparticles decorated-graphene using graphene oxide solution $(1 \mathrm{mg} / \mathrm{mL}$, synthesized via modified Hummer's method) and palladium ions (1 mg $\mathrm{PdCl}_{2}$ in $1 \mathrm{M} \mathrm{KCl}$ ) in a single step using cyclic voltammetry from 0 to $-1.2 \mathrm{~V}$ vs. $\mathrm{Ag} / \mathrm{AgCl}$ at a scan rate of $100 \mathrm{mV} / \mathrm{s}$. The peak current density for ethanol oxidation was found to be $50 \mathrm{~mA}$ $\mathrm{Cm}^{-2}$ which is higher than chemically synthesized PdSn/C [15].

Recently, pulse deposition technique has been used by Hsieh and co-workers to electrochemically deposit Pd [19] on oxidized graphene for proton exchange membrane fuel cells. Star-like Pd clusters consisting of several nanotips are well deposited over the GO sheets, and the primary size of the cluster ranges from 100 to $150 \mathrm{~nm}$. The presence of GO sheets is presumed to render multifunctional roles in facilitating the dispersion of metallic Pd clusters, ionic diffusion, and charge transfer [19]. Some advantages of pulse electrodeposition technique include ease of electrode fabrication and low cost compared to other methods [19]. To the best of our knowledge, there is no report on the pulse electrodeposition of bimetallic PdSn catalyst on graphene oxide for EOR. This study aims to prepare and characterize pulse electrodeposited PdSn catalyst on electrochemically exfoliated graphene oxide. The parameters for pulse electrodeposition of Pd and Sn were optimized based on the current density registered using cyclic voltammetry (CV) towards EOR in basic medium.

\section{Methodology}

Materials and reagents. Precursor salt solutions used for the catalysts such as palladium(II) chloride ( $\mathrm{PdCl}_{2}$ ), tin(II) chloride 
dihydrate $\left(\mathrm{SnCl}_{2} \bullet 2 \mathrm{H}_{2} \mathrm{O}\right)$, potassium bromide $(\mathrm{KBr})$, and sodium hydroxide $(\mathrm{NaOH})$ were all purchased from Sigma Aldrich. Ethanol (J.T. Baker, USA) and sulfuric acid (RCI Labscan, Thailand) are of analytical grade. All solutions were prepared using ultrapure water $(\mathrm{TOC}<5.00 \mathrm{ppb}$; Resistivity $=18.2 \mathrm{M} \Omega \mathrm{cm}$, Millipore, USA).

Preparation of graphene via electrochemical exfoliation. Electrochemical exfoliation of graphite to produce graphene was adapted from Su et al. [20] with minor modification. Graphite plate (Graphtek LLC, USA), 3" × 1", was used as the source of graphene. The graphite plate was clipped on the positive terminal (anode) of the DC power supply and a platinum plate $(3 \mathrm{~cm} \times 1 \mathrm{~cm})$ was clipped to the negative terminal (cathode). The electrodes were submerged in a solution of $0.5 \mathrm{M} \mathrm{H}_{2} \mathrm{SO}_{4}$ and was subjected to a conditioning bias of $+1 \mathrm{~V}$ for 30 min and exfoliating bias of $+6 \mathrm{~V}$ for 5 min. These biases were repeated until a desired of amount of graphene was exfoliated.

The exfoliated graphite material was filtered and washed with ultrapure water to remove excess sulfates. The sulfate-free graphite material was dispersed in N,N-dimethylformamide (DMF) and sonicated for $30 \mathrm{~min}$. The resulting dispersion was centrifuged and decanted to remove the unexfoliated graphite. The electrochemically exfoliated graphene (EGO) material was washed and filtered using $0.45 \mu \mathrm{m}$ membrane filter to remove the DMF. The EGO was dispersed in water and was freeze-dried to obtain powdered EGO[10].

Pulse electrodeposition of Pd and Sn. A solution of $10 \mathrm{mM} \mathrm{PdCl}{ }_{2}$ and $10 \mathrm{mM}$ $\mathrm{SnCl}_{2} \times 2 \mathrm{H}_{2} \mathrm{O}$ in $1 \mathrm{M} \mathrm{HCl}$ was prepared using ultrapure water. The pulse electrodeposition technique was performed with a potentiostat (eDaq, Australia) on a three electrode set-up with the glassy carbon electrode (GCE) as the working electrode, $\mathrm{Ag} / \mathrm{AgCl}$ as the reference electrode, and a platinum rod as the counter electrode. The pulse parameters were varied using the eChem software (v1.6).

Characterization of the catalyst. The electrochemical characterization of the catalyst towards ethanol oxidation reaction was performed with a potentiostat (eDaq, Australia) at a potential range of $-900 \mathrm{mV}$ to $400 \mathrm{mV}$, and at a scan rate of $50 \mathrm{mV} \mathrm{s}^{-1}$. Morphological characterization was done with NX-10 atomic force microscope system (Park Systems, South Korea) in non-contact mode. A PPP-NCHR tip with a tip radius of curvature of $10 \mathrm{~nm}$, nominal frequency of $330 \mathrm{kHz}$, and a force constant of $43 \mathrm{~N} \mathrm{~m}^{-1}$ was used to probe the samples. This was done to observe the topography of the deposited catalyst composites. The surface elemental analysis was performed using ESCALAB 250 XPS system (Thermo Fischer, Theta Probe System, USA) with a monochromatic $\mathrm{Al} \mathrm{K} \alpha$ radiation at $150 \mathrm{~W}$, in the pass energy $(\mathrm{PE})$ mode $(\mathrm{PE}=20 \mathrm{eV})$.

\section{Results AND DISCUSSION}

In Pulse Electro-Deposition (PED), the potential is alternated between two potentials. Each pulse consists of an ON-time and an OFF-time. ONtime is the time where the reduction potential is applied while OFF-time is the time where zero potential is applied. The size and thickness of the deposited catalyst can be controlled by varying the pulse parameters, which can have an influence in the performance of the catalyst [21]. Reduction potentials of $-625 \mathrm{mV}$ and $525 \mathrm{mV}$ were used for the deposition of Pd and Sn, respectively, based on CV measurements of the corresponding metallic solutions on glassy carbon electrode.

Effect of ON-Time and OFF-Time. The synthesis of Pd catalyst on GCE was controlled by varying and optimizing the duration of the pulse parameters, i.e. ON-time and OFF-time. The optimum parameters were chosen based on the 
highest current density $\left(\mathrm{mA} \bullet \mathrm{cm}^{-2}\right)$ of the anodic peak at the positive-going potential scan which is related to electrocatalytic activity towards EOR. This anodic peak, in the potential range of $-0.2 \mathrm{~V}$ to $0.2 \mathrm{~V}$ in the positive-going scan is attributed to the primary oxidation of ethanol mainly as acetate [15].

The ON-time was first optimized while holding the OFF-time constant at $10 \mathrm{~ms}$. The CV curve in Fig. 1 shows that the catalytic activity initially increased to $23.3 \mathrm{~mA} \mathrm{~cm}^{-2}$ with an ON-time of $10 \mathrm{~ms}$. Also, the electrocatalytic activity of Pd towards EOR continuously decrease as ON-time increases. Long deposition times would prolong the growth of the deposited catalyst, resulting in a larger deposit with less effective surface area for EOR [22]. Thus the optimized duration of ON-time was at $10 \mathrm{~ms}$ as it yielded the highest catalytic activity.

The optimized ON-time was then used in the optimization of the OFF-time. The CV curve in Fig. 2 shows the catalytic activity increased when the OFF time was increased. This may be attributed to the mechanism of pulse electrodeposition. During ON-time, $\mathrm{Pd}^{2+}$ ions are reduced to the electrode which produces a concentration gradient at the electrode surface. At short OFF-time, there is not enough time for the $\mathrm{Pd}^{2+}$ ions to diffuse into the concentration gradient near the electrode. This would cause the next cycle to deposit less Pd. Longer duration of OFF-time would provide more time for the ions to diffuse through the bulk, providing enough $\mathrm{Pd}^{2+}$ ions to be deposited on the
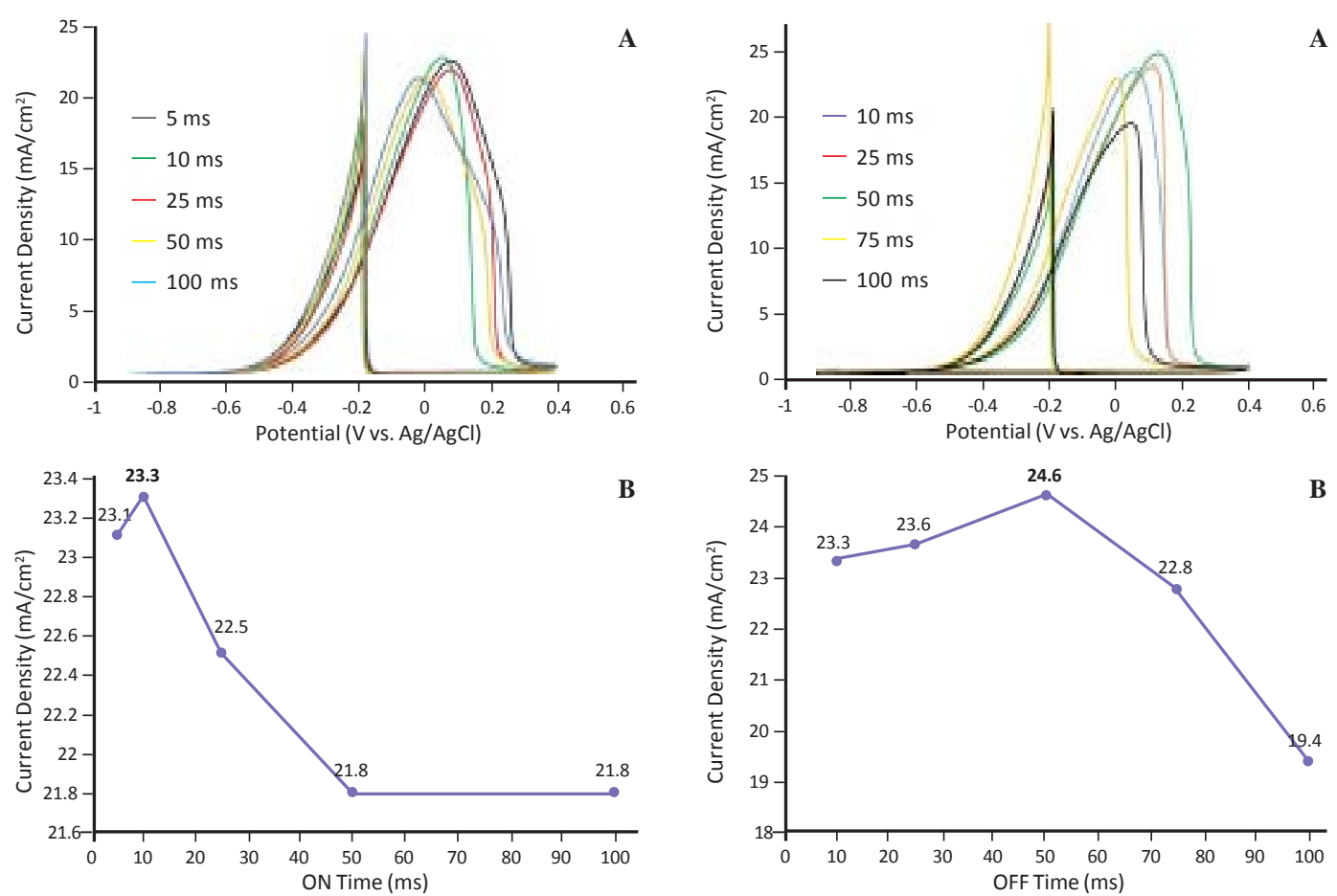

Figure 1. Optimization of the ON-time parameter for the electrodeposition of Pd. The OFF-time parameter was kept constant at $10 \mathrm{~ms}$. (A) CV measurements done using $1 \mathrm{M}$ ethanol in $0.1 \mathrm{M}$ $\mathrm{NaOH}$ and (B) corresponding graph.

Figure 2. Optimization of the OFF-time parameter for the electrodeposition of $\mathrm{Pd}$. The optimized ON-time of 10 ms was used. (A) CV measurements done in $1 \mathrm{M}$ ethanol in $0.1 \mathrm{M}$ $\mathrm{NaOH}$ and (B) corresponding graph. 
electrode [23]. The highest catalytic activity of $24.6 \mathrm{~mA} \mathrm{~m}^{-2}$, was obtained with an OFF-time of $50 \mathrm{~ms}$.

Based on the results, the optimized ON-time and OFF-time were $10 \mathrm{~ms}$ and $50 \mathrm{~ms}$, respectively. These results show that the ON time and OFF

Table 1. Different Ratios of the Number of Pulses for Pd and Sn

\begin{tabular}{c|c|c}
\hline $\begin{array}{c}\text { Ratio of the } \\
\text { number of } \\
\text { pulses }\end{array}$ & $\begin{array}{c}\text { Number } \\
\text { of pulses } \\
\text { for Pd }\end{array}$ & $\begin{array}{c}\text { Number } \\
\text { of pulses } \\
\text { for } \mathbf{S n}\end{array}$ \\
\hline $4: 1$ & 100 & 25 \\
\hline $2: 1$ & 100 & 50 \\
\hline $1: 1$ & 100 & 100 \\
\hline $1: 2$ & 50 & 100 \\
\hline $1: 4$ & 25 & 100 \\
\hline
\end{tabular}
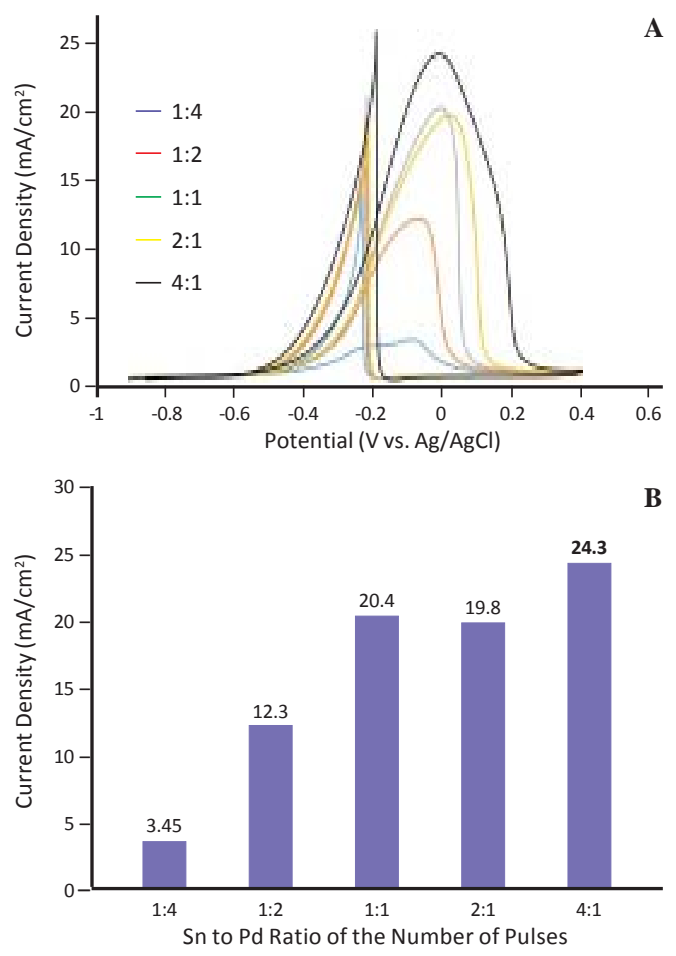

Figure 3. Optimization of $\mathrm{Pd}$ and $\mathrm{Sn}$ ratios with $\mathrm{Sn}$ deposited first on GCE before Pd (i.e. Pd/Sn/ GCE). The ON-time was optimized at $10 \mathrm{~ms}$ and OFF-time was optimized at $50 \mathrm{~ms}$. (A) CV measurements done in $1 \mathrm{M}$ ethanol in $0.1 \mathrm{M}$ $\mathrm{NaOH}$ and (B) corresponding bar graphs. time parameters have an effect towards the electrocatalytic activity of Pd towards EOR.

Effect of Pd:Sn ratio and deposition sequence. As previously stated, the promotional effect of $\mathrm{Sn}$ in Pd-Sn catalysts in the EOR can be explained by the bifunctional effect, in which Sn and/or $\mathrm{SnO}_{\mathrm{x}}$ have stronger interactions with hydroxyl group $\left(\mathrm{OH}_{\mathrm{ads}}\right)$ while Pd has excellent properties in the adsorption and dissociation of ethanol [15]. However, higher Sn content will also decrease the occupancy of active Pd atoms on the surface, and consequently impair the overall performance of dissociation of adsorbed ethanol. Therefore, an optimal Sn content will be observed as a result of such rival effects of Sn when alloying with Pd [15].
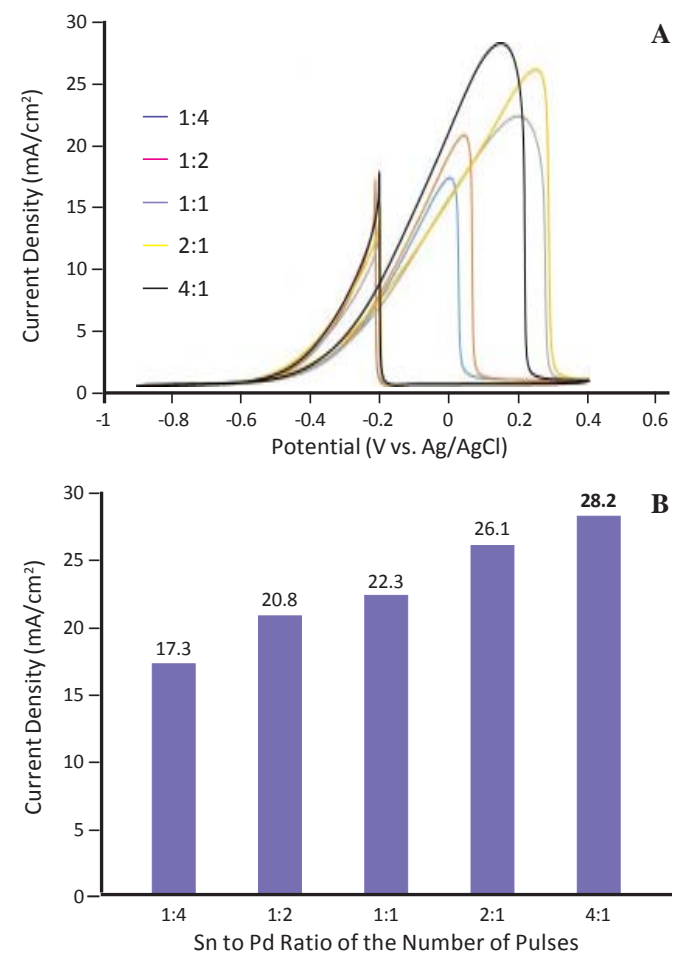

Figure 4. Optimization of $\mathrm{Pd}$ and $\mathrm{Sn}$ ratios with $\mathrm{Pd}$ deposited first on GCE before Sn (i.e. Sn/Pd/ GCE). The ON-time was optimized at $10 \mathrm{~ms}$ and OFF-time was optimized at $50 \mathrm{~ms}$. (A) CV measurements done in $1 \mathrm{M}$ ethanol in $0.1 \mathrm{M}$ $\mathrm{NaOH}$ and (B) corresponding bar graphs. 
Table 1 shows the different ratios of the number of pulses used in depositing the Pd-Sn bimetallic catalyst. The CV data in Fig. 3 and Fig. 4 show the performance of catalysts prepared with different ratios of number of pulses for palladium and tin. The $\mathrm{CV}$ results revealed that the bimetallic catalyst synthesized with a ratio of 4:1 (Pd:Sn) gave the highest current density while the catalyst deposited with a ratio of $1: 2$ and 1:4 yielded even lower current densities. This suggests that, as the number of pulses for Pd was decreased, there were less active Pd sites and more Sn particles deposit which decrease the electrocatalytic activity towards EOR.
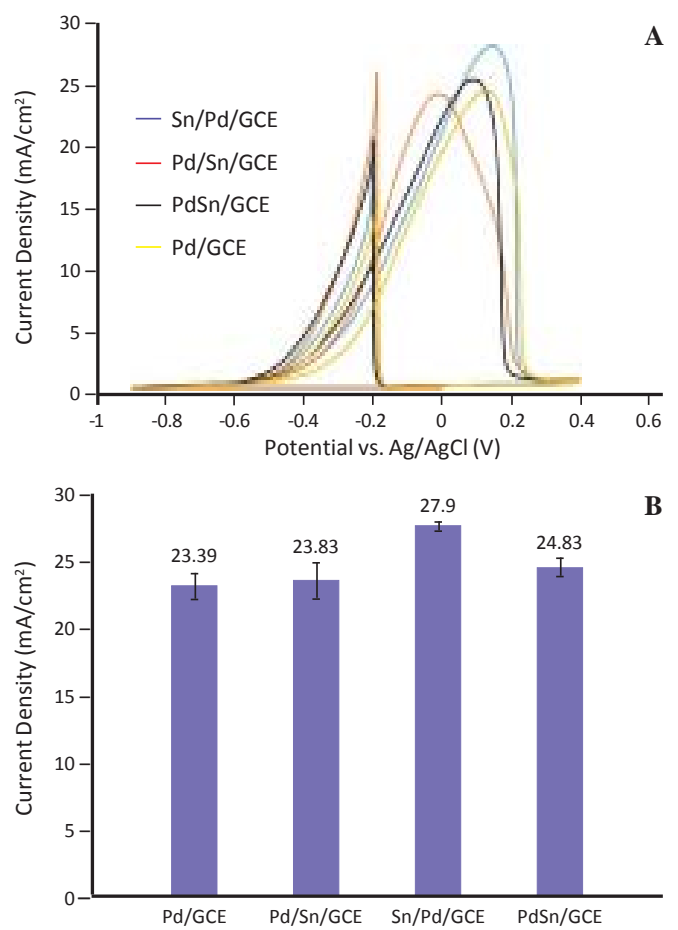

Figure 5. Comparison of sequential and codeposition of Pd and Sn on glassy carbon electrode (GCE) and Pd on GCE. The ratio was optimized at 4:1 Pd:Sn. The ON-time and OFFtime were optimized at $10 \mathrm{~ms}$ and $50 \mathrm{~ms}$, respectively. (A) CV measurements done in $1 \mathrm{M}$ ethanol in $0.1 \mathrm{M} \mathrm{NaOH}$ and (B) corresponding bar graphs showing precision of $\mathrm{CV}$ measurements.
As shown in Fig. 5A, the peak current density is dependent on the sequence of deposition of the alloy. The CV profile shows that depositing Pd first then Sn (Sn/Pd) gave a higher peak current density of $28.2 \mathrm{~mA} \mathrm{~cm}-2$ (Fig. 4) compared to $24.3 \mathrm{~mA} \mathrm{~cm}^{-2}$ when depositing $\mathrm{Sn}$ before Pd (Pd/Sn) (Fig. 3) and $25.4 \mathrm{~mA} \mathrm{~cm}^{-2}$ when co-depositing Pd and Sn (PdSn) (Fig. 5). This may indicate that when $\mathrm{Sn}$ is deposited first before Pd, Sn may have been covered by Pd, and could not provide $\mathrm{OH}^{-}$species that can oxidize adsorbed carbonaceous species, which can improve the catalytic activity of the Pd catalyst.
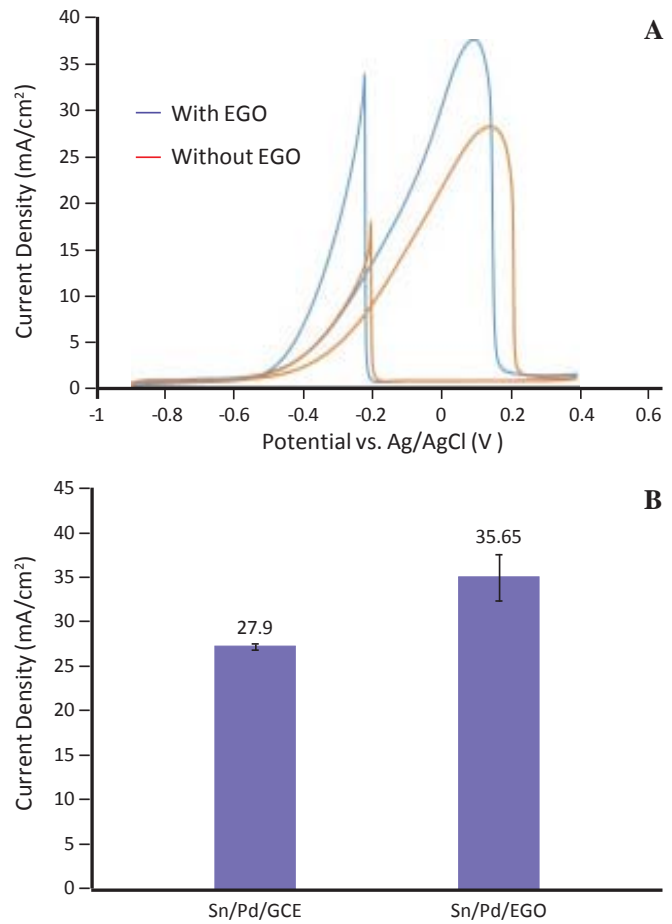

Figure 6. (A) CV profiles of $\mathrm{Sn} / \mathrm{Pd}$ on glassy carbon electrode and Sn/Pd on EGO with Pd deposited first before $S n$ with a ratio of 4:1. The ON-time was optimized at $10 \mathrm{~ms}$ and OFF-time was optimized at $50 \mathrm{~ms}$. CV was done in $1 \mathrm{M}$ ethanol in $0.1 \mathrm{M} \mathrm{NaOH}$. (B) Bar graphs showing the error bars at the range of $+/-1$ SD of the experiment. 
Pulse electrodeposited tin/palladium/exfoliated graphene oxide

Table 2. Repeatability Test of the Optimized Pd/GCE, Pd/Sn/GCE, Sn/Pd/GCE, and PdSn/GCE in Three Trials

\begin{tabular}{|c|c|c|c|c|c|c|}
\hline Catalyst & $\begin{array}{c}\text { Trial } 1 \\
\left(\mathbf{m A} / \mathbf{c m}^{2}\right)\end{array}$ & $\begin{array}{c}\text { Trial } 2 \\
\left(\mathbf{m A} / \mathbf{c m}^{2}\right)\end{array}$ & $\begin{array}{c}\text { Trial } 3 \\
\left(\mathrm{~mA} / \mathbf{c m}^{2}\right)\end{array}$ & $\begin{array}{l}\text { Standard } \\
\text { Deviation } \\
\left(\mathbf{m A} / \mathbf{c m}^{2}\right)\end{array}$ & $\begin{array}{c}\text { Mean } \\
\left(\mathrm{mA} / \mathrm{cm}^{2}\right)\end{array}$ & $\begin{array}{c}\text { Relative } \\
\text { Standard } \\
\text { Deviation } \\
\text { (\%) }\end{array}$ \\
\hline $\mathrm{Pd} / \mathrm{GCE}$ & 24.18 & 22.34 & 23.65 & 0.947 & 23.39 & 4.04 \\
\hline $\mathrm{Pd} / \mathrm{Sn} / \mathrm{GCE}$ & 24.31 & 24.83 & 22.34 & 1.31 & 23.83 & 5.50 \\
\hline Sn/Pd/GCE & 27.73 & 27.86 & 28.12 & 0.20 & 27.90 & 0.71 \\
\hline PdSn/GCE & 25.10 & 25.36 & 24.05 & 0.69 & 24.83 & 2.77 \\
\hline
\end{tabular}

Table 3. Repeatability Test of the Optimized Sn/Pd/GCE and Sn/Pd/EGO for Three Trials

\begin{tabular}{|c|c|c|c|c|c|c|}
\hline Catalyst & $\begin{array}{c}\text { Trial } 1 \\
\left(\mathbf{m A} / \mathbf{c m}^{2}\right)\end{array}$ & $\begin{array}{c}\text { Trial } 2 \\
\left(\mathrm{~mA} / \mathbf{c m}^{2}\right)\end{array}$ & $\begin{array}{c}\text { Trial } 3 \\
\left(\mathrm{~mA} / \mathbf{c m}^{2}\right)\end{array}$ & $\begin{array}{l}\text { Standard } \\
\text { Deviation } \\
\left(\mathrm{mA} / \mathrm{cm}^{2}\right)\end{array}$ & $\begin{array}{c}\text { Mean } \\
\left(\mathrm{mA} / \mathrm{cm}^{2}\right)\end{array}$ & $\begin{array}{c}\text { Relative } \\
\text { Standard } \\
\text { Deviation } \\
(\%)\end{array}$ \\
\hline $\mathrm{Sn} / \mathrm{Pd} / \mathrm{GCE}$ & 28.12 & 27.86 & 27.73 & 0.20 & 27.90 & 0.71 \\
\hline $\mathrm{Sn} / \mathrm{Pd} / \mathrm{EGO}$ & 36.66 & 32.85 & 37.45 & 2.45 & 35.65 & 6.87 \\
\hline
\end{tabular}

To test for precision, CV was done in three separate trials (i.e. three samples of each catalyst system were prepared and the CV towards EOR was measured for each sample) on the optimized Pd/GCE, Pd/Sn/GCE, Sn/Pd/GCE, and PdSn/ GCE. Table 2 shows the current densities of the three trials, the standard deviation, and the relative standard deviation (RSD) for each catalyst. Figure 5B displays the average peak current density of the catalysts together with its corresponding error bars. The RSD values for the samples are low, with Sn/Pd/GCE having the lowest RSD of $0.71 \%$. This suggests that the CV measurements towards EOR for the $\mathrm{Sn} /$ Pd/GCE catalyst composites synthesized through pulse electrodeposition are repeatable.

Electrodepositing the metallic particles on EGO allows proper dispersion of the catalyst by providing nucleation sites for the electrochemical reduction of the catalyst [12]; this could also lessen the use of the catalyst metal without sacrificing its performance. The voltammogram in Fig. 6A shows an improvement on the performance of the catalyst when deposited on EGO, giving a peak current

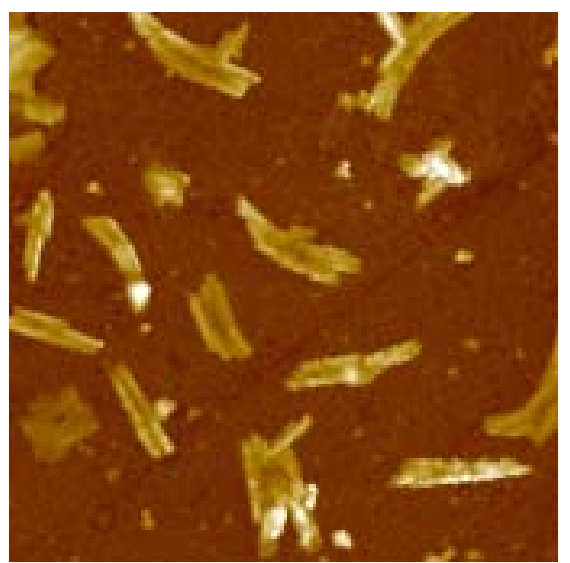

Figure 7. AFM image $(10 \mathrm{~mm} \times 10 \mathrm{~mm})$ of $\mathrm{Sn} / \mathrm{Pd} /$ EGO at a ratio of 1:4. For the synthesis of the catalyst composite, the ON-time and OFF-time were optimized at $10 \mathrm{~ms}$ and $50 \mathrm{~ms}$, respectively.

density of $35.65 \mathrm{~mA} / \mathrm{cm}^{2}$. Repeatability test was done by performing the experiment three times. Table 3 shows the results of each of the three trials, the standard deviations for Sn/Pd/GCE and $\mathrm{Sn} / \mathrm{Pd} / \mathrm{EGO}$. Figure $6 \mathrm{~B}$ displays the average peak current density of the catalysts together with its corresponding error bars. Both catalysts 

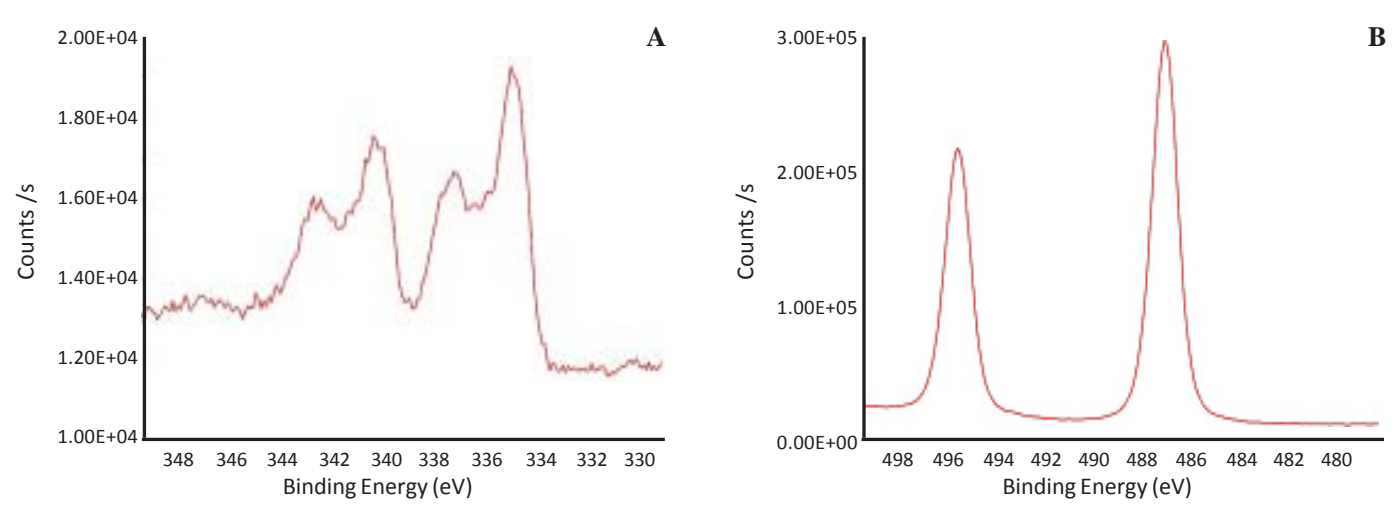

Figure 8. XPS analysis of pulse electrodeposited PdSn on EGO support: (A) Pd 3d and (B) Sn 3d core level spectra.

show RSD of less than $10 \%$. This suggests that fabricating Sn/Pd/EGO through pulse electrodeposition is repeatable.

Morphological characterization. Figure 7 shows bright spherical clusters deposited on graphene surface. This shows the successful deposition and the growth of the Sn/Pd catalysts. Figure 7 shows that the metallic particles appear as bright clusters in wire-like arrangement. This may suggest that graphene did provide deposition sites for $\mathrm{Pd}$, as the $[\mathrm{PdCl}]^{2-}$ ions were first adsorbed on the edges of the oxidized graphene. Under pulsed potential condition, the ionic concentration is sufficiently high to deposit the Pd clusters. With increasing number of potential pulses, the average size of the Pd cluster gradually enlarges, presumably, the bright clusters in wire-like arrangement [19] .

$X$-ray photoelectron spectroscopy analysis. Figure 8A shows the Pd 3d core level spectra of pulse electrodeposited PdSn on EGO support. The two distinct peaks located at $335.6 \mathrm{eV}$ and $340.8 \mathrm{eV}$ can be assigned to the Pd $3 \mathrm{~d}_{5 / 2}$ (highenergy band) and $\mathrm{Pd} 3 \mathrm{~d}_{3 / 2}$ (low-energy band) spin orbit states of metallic Pd, while the less intense doublets around $337.1 \mathrm{eV}$ nd $342.5 \mathrm{eV}$ are attributable to $3 \mathrm{~d}_{3 / 2}$ and $3 \mathrm{~d}_{5 / 2}$ peaks of PdO. The peak assignments are in agreement with a previous study for PdSn catalyst prepared by chemical reduction [17]. Meanwhile, the binding energies of $\operatorname{Sn} 3 d_{5 / 2}(487.3 \mathrm{eV})$ and $3 d_{3 / 2}(496.0 \mathrm{eV})$ for the electrochemically prepared PdSn/EGO composite (Fig. 8B) are higher than those of metallic Sn (485.0 eV and $493.4 \mathrm{eV})$. This indicates the presence of ionic $\mathrm{Sn}$ as $\mathrm{SnO}$ or $\mathrm{SnO}_{2}$ on the surface of Pd-Sn catalyst. The predominance of ionic Sn over metallic Sn has been observed by several studies [15, 17], indicating that the catalyst is PdSn alloy, while Sn atoms on the surface are partially oxidized into $\mathrm{SnO}$ or $\mathrm{SnO}_{2}$.

\section{CONCLUSION}

This study has utilized pulse electrodeposition for the fabrication of Sn/Pd/EGO catalyst. The use of electrochemical techniques has provided a simple and fast method of fabricating high performance catalyst for ethanol oxidation reaction. Cyclic voltammetric studies revealed that pulse parameters such as ON-time and OFFtime, ratio of the binary catalyst, mode and sequence of deposition, among others, have an effect on the performance of the catalyst towards ethanol oxidation reaction. The $\mathrm{Sn} / \mathrm{Pd} /$ EGO catalyst (i.e. Pd deposited first before Sn, with $10 \mathrm{~ms}$ ON-time and $50 \mathrm{~ms}$ OFF time, and a ratio of 4:1 [Pd:Sn]) gave the highest catalytic activity with an average current density of $35.65 \mathrm{~mA} / \mathrm{cm}^{2}$. AFM image showed that the 
catalysts were deposited as bright clusters on graphene surface. XPS analysis confirmed the presence of Pd and Sn which exist in metallic and oxide forms.

\section{ACKNOWLedgment}

The research funding from the Philippine Council for Industry, Energy, and Emerging Technology Research and Development of the Department of Science and Technology (PCIEERD-DOST) is gratefully acknowledged. The authors are grateful as well to the Center for Core Research Facilities, Daegu Gyeongbuk Institute of Science and Technology (DGIST), South Korea, for the XPS analysis.

\section{REFERENCES}

[1] Modibedi R, Masombuka T, \& Mathe M. Carbon supported Pd-Sn and Pd-Ru-Sn nanocatalysts for ethanol electro-oxidation in alkaline medium. International Journal of Hydrogen Energy 2011; 36:4664-4672.

[2] Lamy C, LimaA, LeRhun V, Delime F, Countanceau $C$, \& Leger JM. Recent advance in the development of direct alcohol fuel cells (DAFC). Journal of Power Sources 2002; 105:283-296.

[3] Xu C, Shen P, \& Liu Y. Ethanol electrooxidation on $\mathrm{Pt} / \mathrm{C}$ and $\mathrm{Pd} / \mathrm{C}$ catalysts promoted with oxide. Journal of Power Sources 2007; 164:527-531.

[4] Xu C, Cheng L, Shen P, \& Liu Y. Methanol and ethanol electrooxidation on Pt and Pd supported on carbon microspheres in alkaline media. Electrochemistry Communications 2007; 9:9971001.

[5] Antolini E. Catalysts for direct ethanol fuel cells. Journal of Power Sources 2007; 170:1-12.

[6] Hayre R, Cha SW, Colella W, \& Prinz F. Fuel Cell Fundamentals, $2^{\text {nd }}$ ed. (New York: John Wiley \& Sons, 2008).

[7] Watanabe M \& Motoo S. Electrocatalysis by adatoms: Part II. Enhancement of the oxidation of methanol on platinum by ruthenium ad-atoms. Journal of Electroanalytical Chemistry and Interfacial Electrochemistry 1975; 60(3):267273.

[8] Hsieh C, Wei J, Lin J, \& Yang B. Preparation of Pt-Co nanocatalysts on carbon nanotube electrodes for direct methanol fuel cells. Diamond \& Related Materials 2011; 20:1065-1071.
[9] Wang Y, Wang X, \& Li C. Electrocatalysts of PdCo supported on carbon black or ball-milled carbon nanotubes towards methanol oxidation in alkaline media. Applied Catalysis $B$ : Environmental 2010; 99:229-234.

[10] Tan JL, Villar PG, De Jesus AM, \& Tongol BJV. A green approach to the synthesis of $\mathrm{Pd}-\mathrm{Ni} /$ Graphene via electrochemical exfoliation of graphite from used battery for the electrocatalysis of ethanol. Journal of Chinese Chemical Society 2014; 61:774-777.

[11] Krishna R, Fernandez DM, Ventura J, Freire C, \& Titus E. Facile synthesis of reduced graphene oxide supported Pd@Ni_B/RGO nanocomposite: Novel electrocatalyst for ethanol oxidation in alkaline media. International Journal Hydrogen Energy 2016; 41:11811-11822.

[12] Dong L, Gari RRS, Li Z, Craig MM, \& Hou S. Graphene-supported platinum and platinumruthenium nanoparticles with high electrocatalytic activity for methanol and ethanol. Carbon 2010; 48(3):781-787.

[13] Zhang Z, Xin L, Sun K, \& Li W. Pd-Ni electrocatalysts for efficient ethanol oxidation reaction in alkaline electrolyte. International Journal of Hydrogen Energy 2011; 36(20):1268612697.

[14] Wang Y, Zhao Y, Yin J, Liu M, Dong Q, \& Su Y. Synthesis and electrocatalytic alcohol oxidation performance of $\mathrm{Pd}$-Co bimetallic nanoparticles supported on graphene. International Journal of Hydrogen Energy 2014; 39:1325-1335.

[15] Du W, Mackenzie KE, Milano DF, Deskins NA, Su D, \& Teng X. Palladium-Tin alloyed catalysts for the ethanol oxidation reaction in an alkaline medium. ACS Catalysis 2012; 2:287-297.

[16] Mao H, Wang L, Zhu P, Xiu Q, \& Li Q. Carbonsupported $\mathrm{PdSn}-\mathrm{SnO}_{2}$ catalyst for ethanol electro-oxidation in alkaline media. International Journal of Hydrogen Energy 2014; 39:1758317588.

[17] Feng Y, Bin D, Zhang K, Ren F, Wang J, \& Du Y. One-step synthesis of nitrogen-doped graphene-supported PdSn bimetallic catalysts for ethanol oxidation in alkaline media. RSC Advances 2016; 6:19314-19321.

[18] Nagaraju DH \& Suresh GS. Green chemistry route to the synthesis of palladium nanoparticles on reduced graphene oxide for ethanol fuel cell application. ECS Electrochemistry Letters 2012; 1(2):F1-F3. 
Chang PIA, Tan JL, \& TongolBJV | Acta Manilana 64 (2016)

[19] Hsieh T, Liu Y, \& Roy A. Pulse electrodeposited $\mathrm{Pd}$ nanoclusters on graphene-based electrodes for proton exchange membrane fuel cells. Electrochimica Acta 2012; 64:205-210.

[20] Su CY, Lu AY, Xu Y, Chen FR, Khlobystov AN, \& Li LJ. High-quality thin graphene films from fast electrochemical exfoliation. ACS Nano 2011; 5:2332-2339.

[21] Chandrasekar MS \& Pushpavanam M. Pulse and pulse reverse plating - conceptual, advantages, and applications. Electrochimica Acta 2008; 53:3313-3322.
[22] Jagdeep S, Peiris N, \& Wijayantha U. Rapid and simple potentiostatic deposition of copper(II) oxide thin films. Electrochemistry Communications 2014; 42:68-71.

[23] Hsieh C, Wei J, Hsiao H, \& Chen W. Fabrication of flower-like platinum clusters onto graphene sheets by pulse electrochemical deposition. Electrochimica Acta 2012; 64:177-182. 